\title{
An inguinal herniation of pregnant uterus in a Standard Wirehaired Dachshund - a case report
}

\author{
Lubica Horňáková1, Enrico Stefanizzii , Slavomír Horňák ${ }^{1}$,Zuzana Ševčíková2 \\ Mária Figurová ${ }^{1}$, Marieta Kurillová1, Alexandra Valenčáková-Agyagosová1 \\ University of Veterinary Medicine and Pharmacy, ${ }^{1}$ Small Animal Clinic, \\ ${ }^{2}$ Department of Pathological Anatomy and Pathological Physiology, Košice, Slovakia
}

Received May 29, 2020

Accepted May 26, 2021

\begin{abstract}
A 4-year-old intact female Standard Wirehaired Dachshund dog was referred with chief complaint of inguinal mass to the Small Animal Clinic at the University of Veterinary Medicine and Pharmacy in Košice, Slovakia. On physical examination, the bitch was healthy with no abnormalities other than having a non-painful and non-reducible soft tissue mass in the left inguinal region also involving the mammary gland. Ultrasonographic examination of the abdomen revealed a pregnant uterus and ultrasonography of the inguinal mass showed an organ with a lumen filled with anaechoic fluid. The diagnosis of a herniation was made and the owners decided for complete ovariohysterectomy. The left uterine horn had an incarcerated part of the inguinal hernia together with the ovary. Inside there was one macerated conceptus. The remaining part of the left uterine horn was located in the abdomen and had 2 macerated conceptuses. The bitch made an uneventful recovery from the surgery and anaesthesia with no postoperative complications and was sent home after the surgical procedure.
\end{abstract}

Inguinal mass, uterine horns, pregnancy, foetuses

The term hernia is used where the defect is congenital due to a failure of embryonic signalling and fusion, and a distinct hernia ring and sac exist. The term rupture is used where the defect is acquired, typically traumatically. Ruptures do not have a distinct hernia ring and sac. Therefore, although the terms "hernia" and "rupture" are not synonymous, for certain conditions they are used interchangeably. Describing the anatomical locations is probably the most common way of classifying hernias. We know for example umbilical, inguinal, femoral, hiatal or perineal hernias. External abdominal hernias are defects in the external abdominal wall that allow protrusion of abdominal contents. Internal abdominal hernias are those that occur through a ring of tissue contained within the abdomen, e.g. hiatal hernia (Pratschke 2014).

An inguinal hernia is a protrusion of an organ or part of an organ, fat or tissue through the inguinal ring, i.e. the region in the groin where the abdominal musculature meets the back legs. Factors potentially involved in the development of inguinal hernias may be anatomical, hormonal, and/or metabolic in nature. However, the causes of inguinal herniation in small animals are poorly understood (Byers et al. 2007). Contents of inguinal hernia may include the omentum, fat, ovary, uterus, small intestine, colon, bladder and spleen. These hernias are often chronic and do not cause clinical signs until pregnancy or pyometra develops (Fossum 2002). Congenital inguinal hernias in dogs are more common in males than females, possibly due to delayed inguinal ring narrowing associated with the testicular descent, while acquired inguinal hernias are far more common in females associated with oestrogen levels (Fox 1963). In the bitch, acquired inguinal hernia, through which the uterus may herniate is relatively common. The incarcerated uterus then often becomes the focus of pregnancy. The condition can also occur in the cat but it is rare in this species. The 
hernia is generally unilateral and may contain one or both uterine horns. Often the history is that an inguinal swelling the size of a hen's egg has been recognised by the owner for months, but that during the last few weeks it has rapidly become larger. In other cases the recent development of a progressive swelling is the story. There may or may not be a history of recent oestrus and mating. The lesion is obvious and, if careful examination is carried out, it is unlikely that it will be confused with a mammary neoplasm or a local abscess. The condition is painless, and there is no systemic disturbance (Parkinson et al. 2019).

Although it is tense and irreducible, there is little tendency for strangulation, provided the intestine is not involved. The latter complication is rare. In those cases in which pregnancy is advanced, it will be probably possible to detect foetuses on palpation, which can be confirmed by transabdominal ultrasonography. The course of the condition depends primarily on the degree of tension in the hernial sac, and this will be influenced by its size and the number of foetuses involved. Sometimes, the foetuses will develop normally up to a certain point and then die, probably because of impaired blood supply to the herniated parts of the uterine horns, and then undergo resorption. The majority of cases will be presented when pregnancy has advanced about 30 days and each foetal unit is about the size of a golf ball, and by this time the swelling is alarming the owner. It is very unlikely, but not impossible, for such a pregnancy to go to term with subsequent dystocia (Parkins on et al. 2019). Contributing factors for inguinal hernia may include weakening of the abdominal wall structures from nutritional or metabolic problems and obesity (Smeak 2003) and can cause significant health consequences in the long term (Pošiváková et al. 2017).

The foetus may die if the blood supply is compromised but when it is diagnosed promptly, the hernia can be explored surgically, the trapped uterus released and the hernia repaired. If problems occur at parturition, the hernia may be emptied during a caesarean section. This case report describes the successful surgical management of inguinal herniation of a pregnant uterine horn in a Standard Wirehaired Dachshund dog.

\section{Case presentation}

A four-year-old $8.8 \mathrm{~kg}$ intact female Standard Wirehaired Dachshund dog was referred with chief complaint of inguinal mass to the Small Animal Clinic at the University of Veterinary Medicine and Pharmacy in Košice, Slovakia.

\section{Clinical examination}

Clinical examination revealed a normal heart rate and normal respiratory rate, a rectal temperature of $37.8^{\circ} \mathrm{C}$, pink mucous membranes with a capillary refill time under $2 \mathrm{~s}$ and a good body condition. On physical examination, the bitch was healthy with no abnormalities other than having a non-painful and non-reducible soft tissue mass in the left inguinal region involving also the mammary gland (Plate VIII, Fig. 1). The bitch had no difficulty urinating or defecating. Following the clinical examination, venous blood was taken from the v. cephalica antebrachii. Blood samples were placed into test tubes with ethylenediamine tetraacetic acid for haematology and agglutinative gel was added for biochemistry using sterile single-use needles $(21 \mathrm{G} \times 38 \mathrm{~mm}, 0.8 \times 38 \mathrm{~mm})$. The blood was then centrifuged at $1,372 \times g$ for $10 \mathrm{~min}$ (Eppendorf centrifuge 5702, max RCF 3,000 $\times g$ ), where blood serum was separated. Haematology results (Table 1) and serum biochemistry results (Table 2) were unremarkable.

\section{Ultrasound examination}

Ultrasonography of the abdomen revealed a pregnant uterus (Plate VIII, Fig. 2) and ultasonography of the inguinal mass revealed an organ with a lumen filled with anaechoic fluid (Plate IX, Fig. 3). Based upon the history, physical examination, and diagnostic test 
Table 1. Haematology results ProCyteDx.

\begin{tabular}{|c|c|c|}
\hline Indicator & Measured value & Reference values \\
\hline $\mathrm{RBC}$ & $5.64 \times 10^{12} / 1$ & $5.65-8.87 \times 10^{12} / 1$ \\
\hline HCT & $36.10 \%$ & $37.3-61.7 \%$ \\
\hline HGB & $12.6 \mathrm{~g} / \mathrm{dl}$ & $13.1-20.5 \mathrm{~g} / \mathrm{dl}$ \\
\hline $\mathrm{MCV}$ & $64.0 \mathrm{fl}$ & $61.6-73.5 \mathrm{fl}$ \\
\hline $\mathrm{MCH}$ & $22.3 \mathrm{pg}$ & $21.2-25.9 \mathrm{pg}$ \\
\hline $\mathrm{MCHC}$ & $34.9 \mathrm{~g} / \mathrm{dl}$ & $32.0-37.9 \mathrm{~g} / \mathrm{dl}$ \\
\hline RDW & $16.00 \%$ & $13.6-21.7 \%$ \\
\hline$\%$ RETIC & $0.70 \%$ & \\
\hline RETIC & $36.7 \mathrm{~K} / \mu \mathrm{l}$ & $10.0-110.0 \mathrm{~K} / \mu \mathrm{l}$ \\
\hline RETIC-HGB & $22.6 \mathrm{pg}$ & $22.3-29.6 \mathrm{pg}$ \\
\hline WBC & $11.86 \times 10^{9} / 1$ & $5.05-16.76 \times 10^{9} / 1$ \\
\hline$\% \mathrm{NEU}$ & $67.20 \%$ & \\
\hline$\%$ LYM & $18.50 \%$ & \\
\hline$\%$ MONO & $9.40 \%$ & \\
\hline$\%$ EOS & $4.80 \%$ & \\
\hline$\%$ BASO & $0.10 \%$ & \\
\hline NEU & $7.97 \times 10^{9} / 1$ & $2.95-11.64 \times 10^{9} / 1$ \\
\hline LYM & $2.20 \times 10^{9} / 1$ & $1.05-5.10 \times 10^{9} / 1$ \\
\hline MONO & $1.11 \times 10^{9} / 1$ & $0.16-1.12 \times 10^{9} / 1$ \\
\hline EOS & $0.57 \times 10^{9} / 1$ & $0.06-1.23 \times 10^{9} / 1$ \\
\hline BASO & $0.01 \times 10^{9} / 1$ & $0.00-0.10 \times 10^{9} / 1$ \\
\hline PLT & $547 \mathrm{~K} / \mu \mathrm{l}$ & $148-484 \mathrm{~K} / \mu 1$ \\
\hline MPV & $9.4 \mathrm{fl}$ & $8.7-13.2 \mathrm{fl}$ \\
\hline PDW & $11.5 \mathrm{fl}$ & $9.1-19.4 \mathrm{fl}$ \\
\hline PCT & $0.52 \%$ & $0.14-0.46 \%$ \\
\hline
\end{tabular}

Band neutrophils - when presence suspected, basophils - \% and total, eosinophils - \% and total, HCT - haematocrit, HGB - haemoglobin, lymphocytes - \% and total, MCH - mean cell haemoglobin, MCHC - mean cell haemoglobin concentration, MCV - mean cell volume, monocytes - \% and total, MPV - mean platelet volume, neutrophils - \% and total, nRBCs - nucleated red blood cells-when presence suspected, PCT - platelet haematocrit, PDW - platelet distribution width, PLT - platelet count, RBC - red blood cell count, RDW - red blood cell distribution with, RETIC - \% and total /reticulocyte count/ percentage of reticulocytes, RETIC-HGB - reticulocyte haemoglobin, WBC - white blood cell count

Table 2. Serum biochemistry results Catalyst One.

\begin{tabular}{lcr}
\hline Indicator & Measured values & Reference values \\
\hline GLU & $10.94 \mathrm{mmol} / 1$ & $4.11-7.95 \mathrm{mmol} / 1$ \\
CREA & $27 \mu \mathrm{mol} / 1$ & $44-159 \mu \mathrm{mol} / 1$ \\
UREA & $3.6 \mathrm{mmol} / 1$ & $2.5-9.6 \mathrm{mmol} / 1$ \\
BUN/CREA & 34 & \\
TP & $61 \mathrm{~g} / 1$ & $52-82 \mathrm{~g} / 1$ \\
ALB & $27 \mathrm{~g} / 1$ & $23-40 \mathrm{~g} / 1$ \\
GLOB & $35 \mathrm{~g} / 1$ & $25-45 \mathrm{~g} / 1$ \\
ALB/GLOB & 0,8 & $10-125 \mu \mathrm{kat} / 1$ \\
ALT & $15 \mu \mathrm{kat} / 1$ & $23-212 \mu \mathrm{kat} / 1$ \\
ALKP & $93 \mu \mathrm{kat} / 1$ & \\
\hline
\end{tabular}

ALB - albumin, ALKP - alkaline phosphatase, ALT - alanine aminotransferaze, BUN/CREA - blood urea nitrogen/ creatinine, CREA - creatinine, GLU - glucose, GLOB - globulin, TP - total protein, UREA - urea 
results, a presumptive diagnosis of inguinal herniation of the left uterine horn was made. The owner opted for surgery and complete ovariohysterectomy.

\section{Surgical procedure and post-operative care}

The bitch was premedicated by administration of butorphanol $0.2 \mathrm{mg} / \mathrm{kg}$ i.v. (Butomidor $10 \mathrm{mg} / \mathrm{ml}$; Richter Pharma AG, Wels, Austria) and medetomidin hydrochloridum $0.015 \mathrm{mg} / \mathrm{kg}$ i.v. (Cepetor 1mg/ml; CP Pharma Handelsgesellschaft mbH, Burgdorf, Germany). Anaesthesia was induced with propofol $4 \mathrm{mg} / \mathrm{kg}$ i.v. (Propofol 1\% MCT/LTC; Fresenius Kabi, Bad Homburg, Germany), followed by endotracheal intubation. Anaesthesia was maintained with isofluorane (Isoflurin $1000 \mathrm{mg} / \mathrm{g}$; VETPHARMAANIMAL HEALTH, S.L., Barcelona, Spain) and oxygen. The patient was placed in dorsal recumbency and the ventral abdomen was aseptically prepared in the standard fashion. After preparation of the surgical site, a skin incision was made over the swelling in the inguinal region.

The subcutaneous tissue was undermined to allow exposure of the hernial ring and hernial sac, which consisted of the left uterine horn (Plate IX, Fig. 4). There was an inflammatory reaction found in the form of exudate present in the subcuatenous tissue. An incision into the herniated uterine horn was performed to remove the content and reduce volume (Plate X, Fig. 5). Coeliotomy was performed in the next phase and the pregnant uterine horn was exteriorized (Plate X, Fig. 6). After exteriorization of the uterus and evacuation of the contents of the hernia, we placed double ligatures under both ovaries and the uterine body. Sutures were both circular and penetrating, using an absorbable suture material (Polydox EP3; CHIRANA T. Injecta, s.r.o., Prague, Czech Republic) and complete ovariohysterectomy was performed (Plate XI, Fig. 7). The abdominal cavity was controlled for possible haemorrhages. After checking that there was no active bleeding in the area, we sutured all the layers. Suture of the abdominal wall was performed in a standard way, the peritoneum and muscles with a continuous stitch by Reverdin. The subcutis was sutured with a simple continuous suture pattern. Absorbable suture material Polydox EP3 (CHIRANA T. Injecta, s.r.o.) was used for all of these sutures. For the intradermal suture we used absorbable suture material Polydox EP2 (CHIRANA T. Injecta, s.r.o.). In the end, we sutured the herniated space using a singular X stitch on the muscles using absorbable suture material Polydox EP3 (CHIRANA T. Injecta, s.r.o.). The subcutis was sutured with a simple continuous suture pattern using absorbable suture material Polydox EP3 (CHIRANA T. Injecta, s.r.o.) and the intradermal suture using absorbable suture material Polydox EP2 (CHIRANA T. Injecta, s.r.o.).

In the right uterine horn we found 4 distinct little sacs of a diameter of $4 \mathrm{~cm}$, with vital and developed conceptuses for the stage of pregnancy inside each. The left uterine horn had an incarcerated part in the inguinal hernia together with the ovary. Inside there was one macerated conceptus (Plate XII, Fig. 8). The remaining part of the uterine horn was located in the abdomen and also had two macerated conceptuses. On the left ovary five corpora lutea were found and on the right ovary there were two corpora lutea present at the time of surgery.

The non-steroidal inflammatory drug meloxicam $0.04 \mathrm{mg} / \mathrm{kg}$ s.c. (Meloxidolor $5 \mathrm{mg} / \mathrm{ml}$; Le Vet Beheer B.V., Oudewater, Netherlands) was administered postoperatively to control pain. Before surgery amoxicillin with clavulanic acid $15 \mathrm{mg} / \mathrm{kg}$ s.c. (Synulox RTU $100 \mathrm{ml}$; Zoetis, Prague, Czech Republic) was applied, with a continuing per os administration for 7 days (Synulox; Zoetis). The bitch made an uneventful recovery from the surgery and anaesthesia with no postoperative complications and was sent home after the surgical procedure. The bitch came back for a routine check-up and after two months there was no evidence that she had undergone such a complication.

\section{Histological examination}

During the surgery, pieces of tissue were taken for histopathological evaluation. Samples of $0.5 \mathrm{~cm}^{3}$ were immediately fixed in $10 \%$ formalin for $48 \mathrm{~h}$. Subsequently, the samples 
were processed by standard histological techniques. The sections were embedded in paraffin and stained with haematoxylin and eosin. All slides were examined under light microscope (Microscope RED-223 LED, Motic, Camera Moticam 3+, 3.0 MP, China) with $\times 40$ and $\times 100$ magnifications. The villous structure of trophoblast surrounded with mesoderm was observed (Plate XII, Fig. 9A). Villous stroma with foetal vessels, syncytiotrophoblast and cytotrophoblast were found as well (Plate XIII, Fig. 9B).

\section{Discussion}

Inguinal hernia occurs more often in middle-aged intact bitches and may be caused by the stretching of the abdominal wall due to old age. Hernia may result from congenital defects or from blunt trauma with increased abdominal pressure. They are also often seen in bitches with apparent enlargement of the uterus due to pyometra or pregnancy (Serin et al. 2009). This was seen also in our case. We suspect that with the advancement of pregnancy and enlargement of the uterus, a blunt trauma could have helped to develop the condition. The bitch in this case was used as a hunting dog, so a blunt trauma is possible. Obesity is another factor that increases intra-abdominal pressure, thus forcing peritoneal adipose tissue into the inguinal canals. The vaginal process and inguinal canal may be dilated secondary to accumulation of fat surrounding the round ligament, thus predisposing the dog to potential herniation (Fossum 2002).

In our case, the bitch had a normal amount of adipose tissue and was not obese, but the correlation between obesity and herniation is strong. The clinical signs range from a painless inguinal mass to signs related to incarcerated or non-viable small intestine (Jahmromi et al. 2009). In our case, the bitch was growing a non-painful mass in the left inguinal region and the owners noticed it only because it was slowly increasing in size. The hernia was not causing the dog any problems, which means that the herniated uterus and blood supply were not strangulated by the hernia. Seroma or haematoma formation is the most common complication of inguinal hernia repair, typically from inadequate haemostasis or excessive tissue handling during surgery, complicated by the high motion nature of the site. Exercise restriction and wound hygiene are important after surgery, and gentle massage with warm compresses may help to reduce fluid retention. Entrapment of neurovascular structures passing through the canal will cause obvious pain postoperatively, and in people a chronic pain syndrome is well recognized as a complication of inguinal and femoral hernia repair (Chan and Chan 2008). The bitch in our case had just a small subcutaneous haematoma that resolved in a short period of time. The bitch showed no signs of postoperative complications, no signs of recurrence or further disease or pain which shows that in this particular case there was no problem with entrapment of any neurovascular structures passing through.

As with all hernias, strangulation and incarceration can have a major adverse effect on the prognosis. A complication rate of $17 \%$ was described in one report of 35 dogs, with a 3\% mortality rate (Waters et al. 1993). As inguinal hernias typically appear during oestrus or in pregnant bitches, oestrogen is believed to play a major role in the development of these types of hernias (Fossum 2002; Byers et al. 2007). Sex hormones may change the strength and character of the connective tissue, thereby weakening and enlarging the inguinal rings (Smeak 2003). We can agree with this supposition because most of the rare cases were definitely pregnant bitches or bitches in heat which confirms the role of oestrogen in having a major role in the formation of inguinal hernia in the bitch.

Another hormone that may affect the fate of hernia formation and hernia repair is relaxin. It is released from the placenta during pregnancy. It relaxes pelvic ligaments and softens and widens the cervix. Relaxin reduces extracellular matrix synthesis and induces collagen degradation (Samuel et al. 2007). In a study on rats, relaxin caused a significant reduction 
in the tissue collagen content (Samuel et al. 1998). Therefore, we can say there may be a risk of recurrence when the repair is done. The relaxin level is high, although there is no evidence for this supposition. It has been reported that there is a higher expression of relaxin receptors within the muscles of the pelvic diaphragm in dogs with a perineal hernia. This may suggest that relaxin plays also a role in the pathogenesis of formation of this type of hernia by causing muscular atrophy (Merchav et al. 2005).

\section{Conclusion}

In this report we analysed a case of a pregnant uterus inguinal herniation, which the owners of the bitch were unaware of. Inguinal hernia of pregnant uterine horns through the inguinal ring can result in dystocia and therefore, surgical repair of the hernia should be accomplished as soon as possible in order to prevent the ischaemic compromise of the growing foetus. Caesarean section may be required to deliver term pups that have herniated. This shows that although it is a rare condition, we need to take it into consideration when treating complications during pregnancy and parturition. The bitch in the present case did not show any postoperative complications. Two months later, the bitch was re-examined and clinical and laboratory examinations were all normal. The bitch was completely healthy with no signs of recurrence or further disease.

\section{Acknowledgements}

This publication was created within the project of the Medical University Park in Košice (MediPark, Košice), Phase I, ITMS: 26220220185, supported by the Operational Program Research and Development financed from the European Regional Development Fund (OP VaV2012/2.2/08-RO) contracts: OPVaV/12/2013.

\section{References}

Byers CG, Williams JE, Saylor DK 2007: Pyometra with inguinal herniation of the left uterine horn and omentum in a Beagle dog. J Vet Emerg Crit Care 17: 86-92

Fossum TW 2002: Surgery of the Abdominal Cavity In: Fossum TW, Choyl SH, Doland AH, Ann LJ. Howard BS, Michae DW (Eds): Small Animal Surgery. Second Edition. Mosby Inc Missouri, 1400 p.

Fox MW 1963: Inherited inguinal hernia and midline defects in the dog. J Am Vet Med Assoc 143: $602-604$

Chan G, Chan CK 2008: Longterm results of a prospective study of 225 femoral hernia repairs: indications for tissue and mesh repairs. J Am Coll Surg 207: 360-366

Jahromi AR, Nazhwani SD, Gandmani MJ, Mehrshad S 2009: Concurrent bilateral inguinal and umbilical hernias in a bitch: a case report. Vet Arhiv 79: 517-522

Merchav R, Feuerman Y, Shamy A, Ranen E, Stein U, Johnston DE, Shahar R 2005: Expression of relaxin receptor LRG7, canine relaxin, and relaxin-like factor in the pelvic diaphragm musculature of dogs with and without perineal hernia. Vet Surg 34: 476-481

Parkinson TJ, Vermunt JJ, Noakes DE 2019: Maternal Dystocia: Causes and Treatment. In: Noakes DE, Parkinson TJ, England GCW (Eds.): Veterinary Reproduction and Obstetrics. 10 ${ }^{\text {th }}$ edn. Saunders Elsevier Ltd., Edinburgh, Scotland, $837 \mathrm{p}$.

Pošiváková T, Hromada R, Veszelits Laktičová K, Vargová M, Takáč L, Švajlenka J, Pošivák J, Cimboláková I 2017: The effect of heavy metals in the water source on selected biochemical indices in European mouflon (Ovis musimon L.) from a game reserve. Acta Vet Brno 86: 45-49

Pratschke KM 2014: Abdominal wall hernias and ruptures. In: Langley-Hobbs SJ, Demetriou JL, Ladlow JF (Eds): Feline Soft Tissue and General Surgery. $1^{\text {st }}$ edn. Saunders Elsevier Ltd., 768 p.

Samuel CS, Lekgabe ED, Mookerjee 1 2007: The effects of relaxin on extracellular matrix remodeling in health and fibrotic disease. Adv Exp Med Biol 612: 88-103

Samuel CS, Coghlan JP, Bateman JF 1998: Effects of relaxin, pregnancy and parturition on collagen metabolism in the rat pubic symphysis. J Endocrinol 159: 117-125

Serin G, Yaygingul R, Tarimcilar T, Sarierler M 2009: An incarcerated inguinal hysterocele in a pregnant bitch: a case report. Vet Med 54: 382-386

Smeak DD 2003: Abdominal Hernias. In: Slatter D (Ed.): Text Book of Small Animal Surgery. $3^{\text {rd }}$ edn. W.B. Sunders, Philadelphia, U.S.A, pp. 452-455

Waters DJ, Roy RG, Stone EA 1993: Retrospective study of inguinal hernia in 35 dogs. Vet Surg 22: 44-49 
Horňáková L'. et al.: An inguinal... pp. 185-190

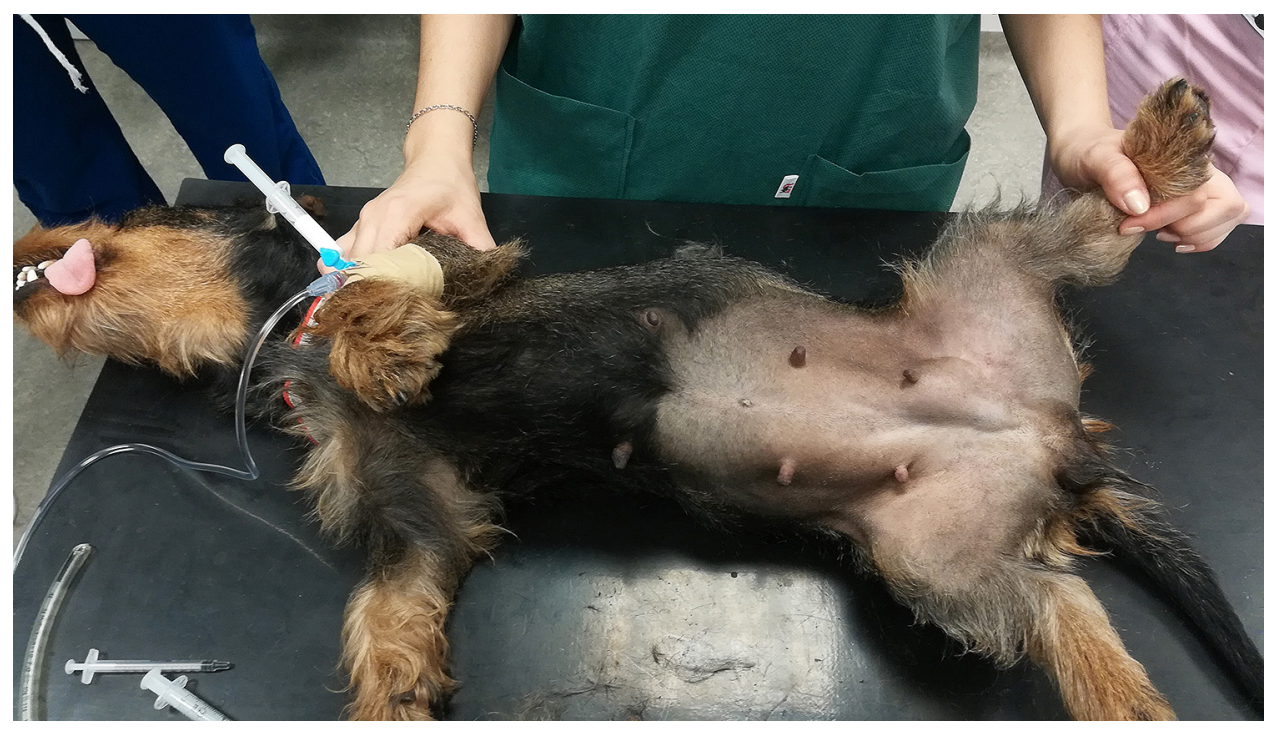

Fig. 1. The soft tissue mass in the left inguinal region of the female Dachshund

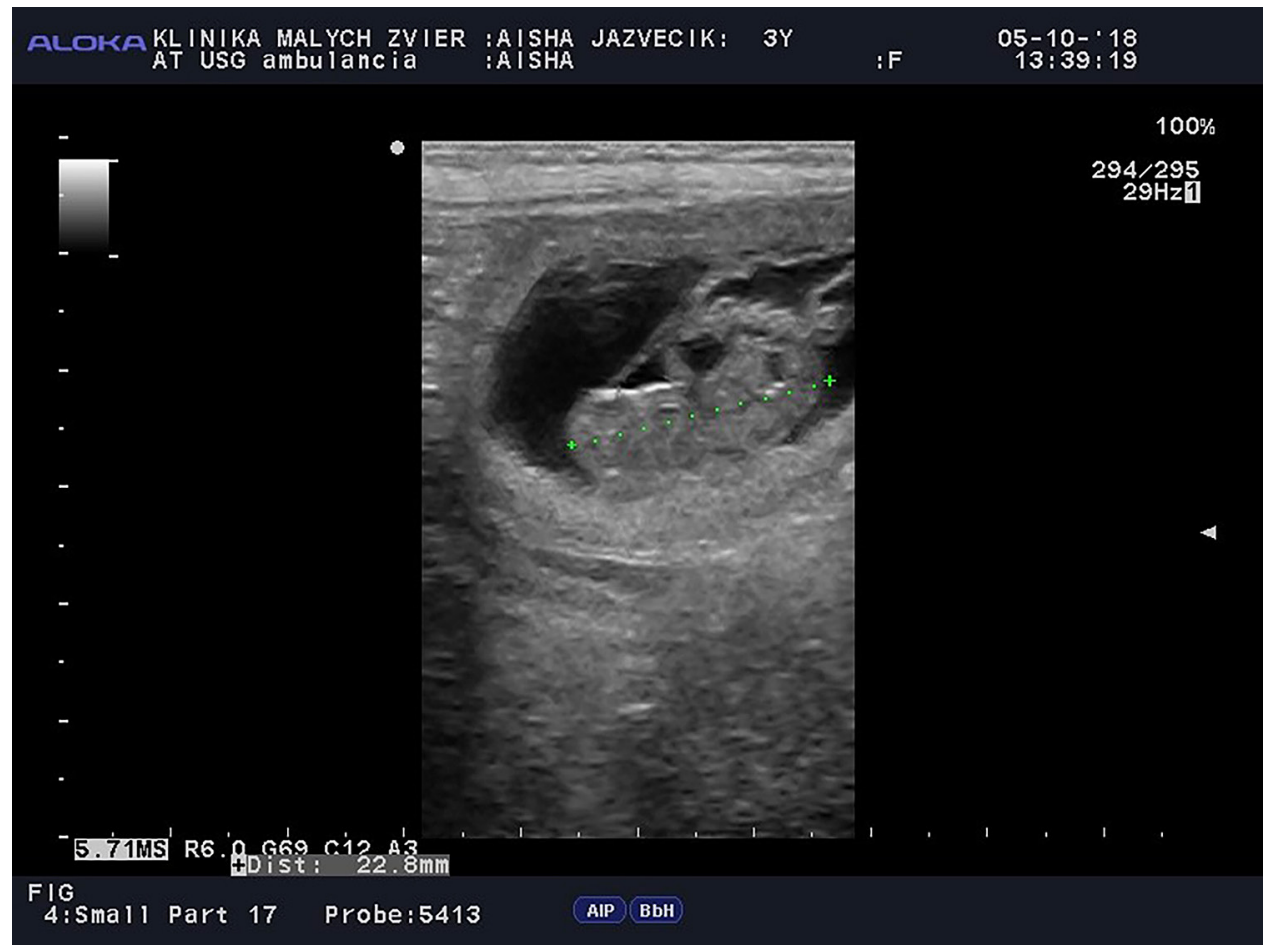

Fig. 2. Ultrasonography of the abdomen with a pregnant uterus 


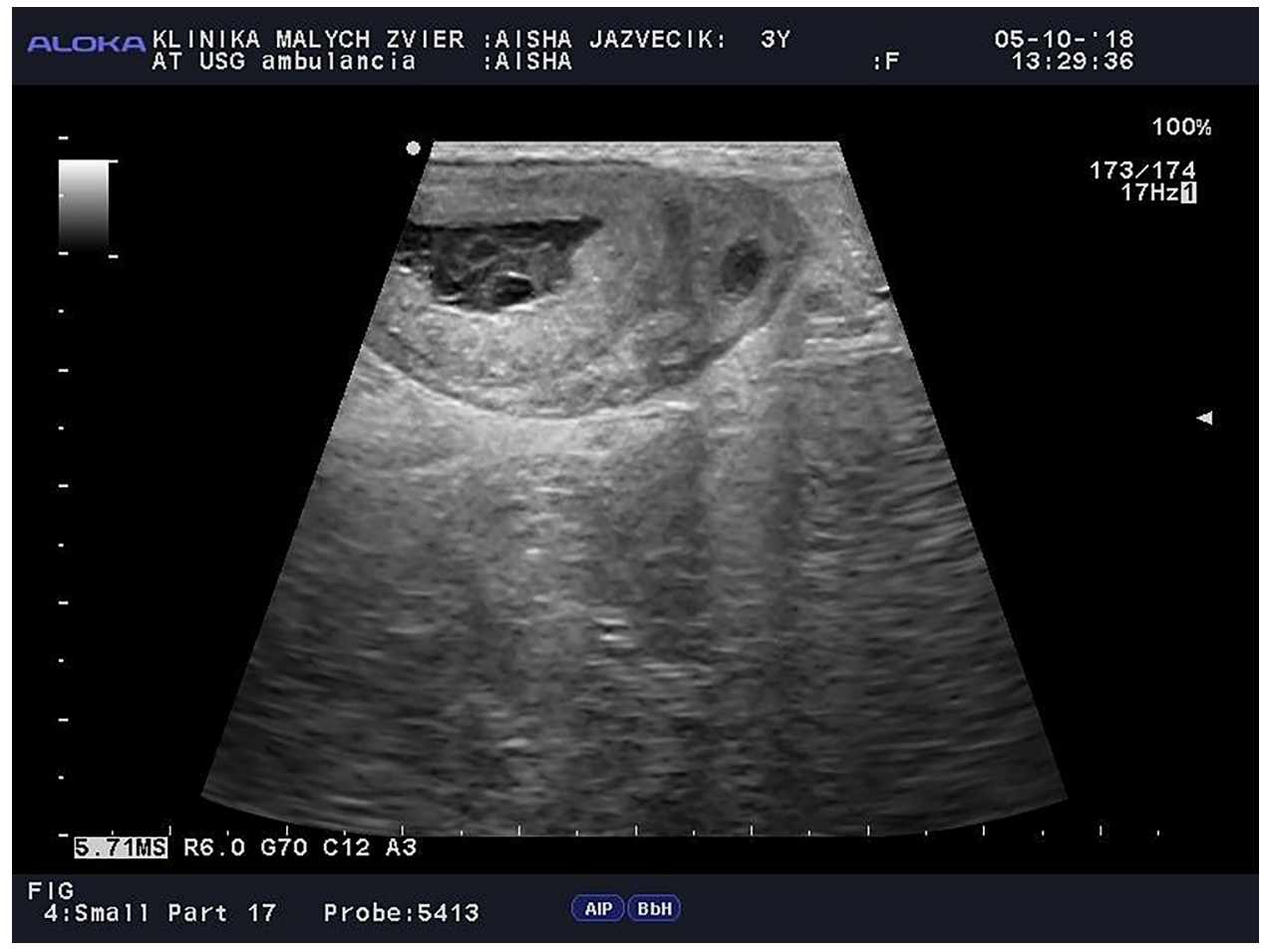

Fig. 3. Ultrasonography of the left inguinal mass

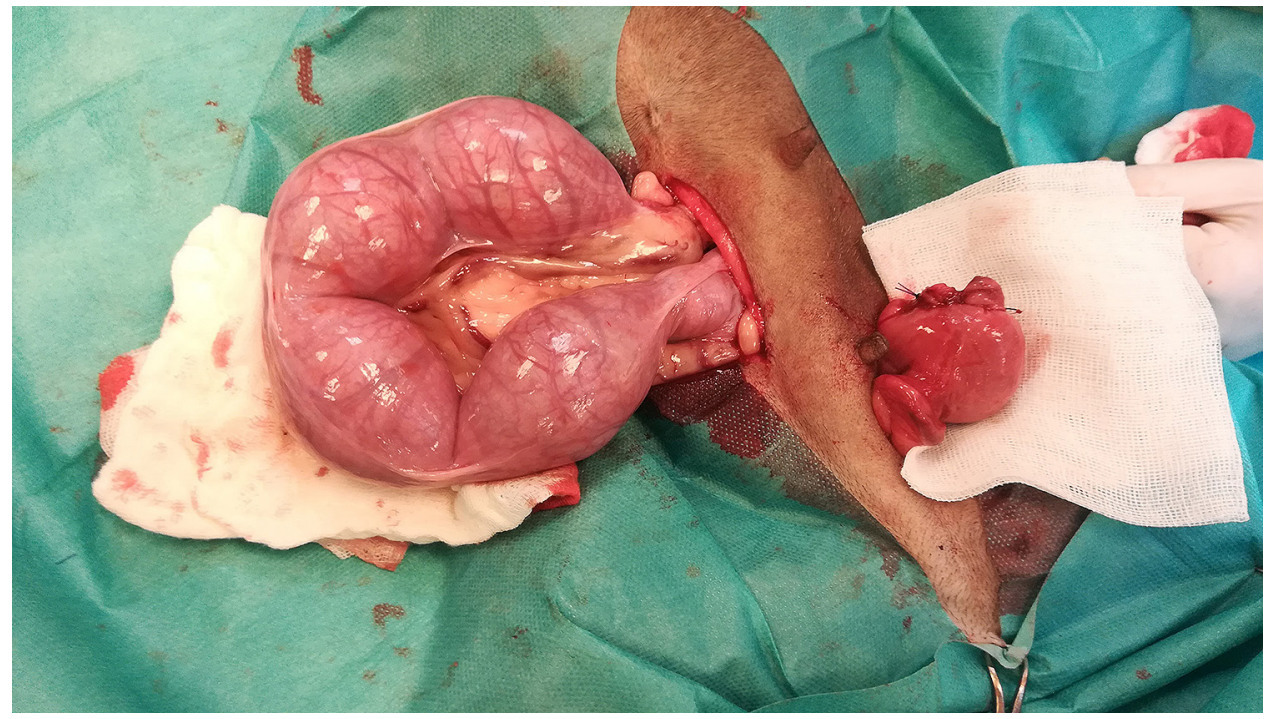

Fig. 4. Exposure of the hernial ring and the hernial sac 
Plate X

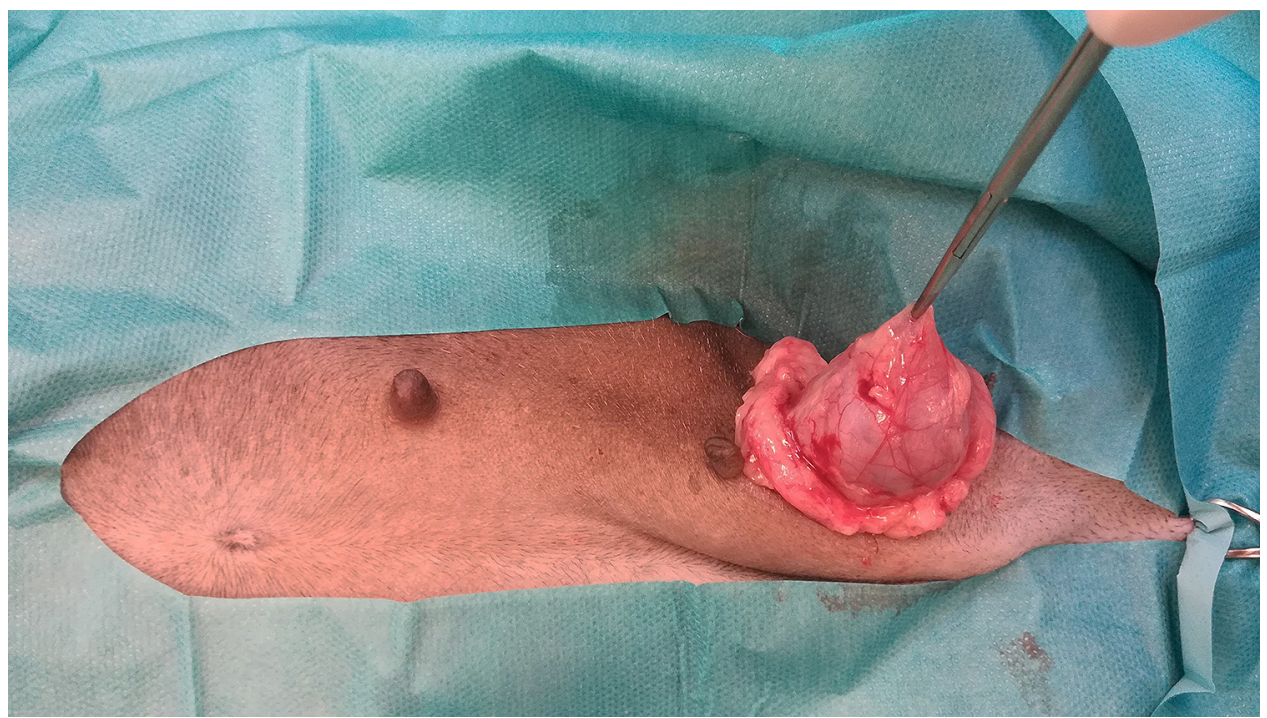

Fig. 5. Incision of the herniated uterine horn

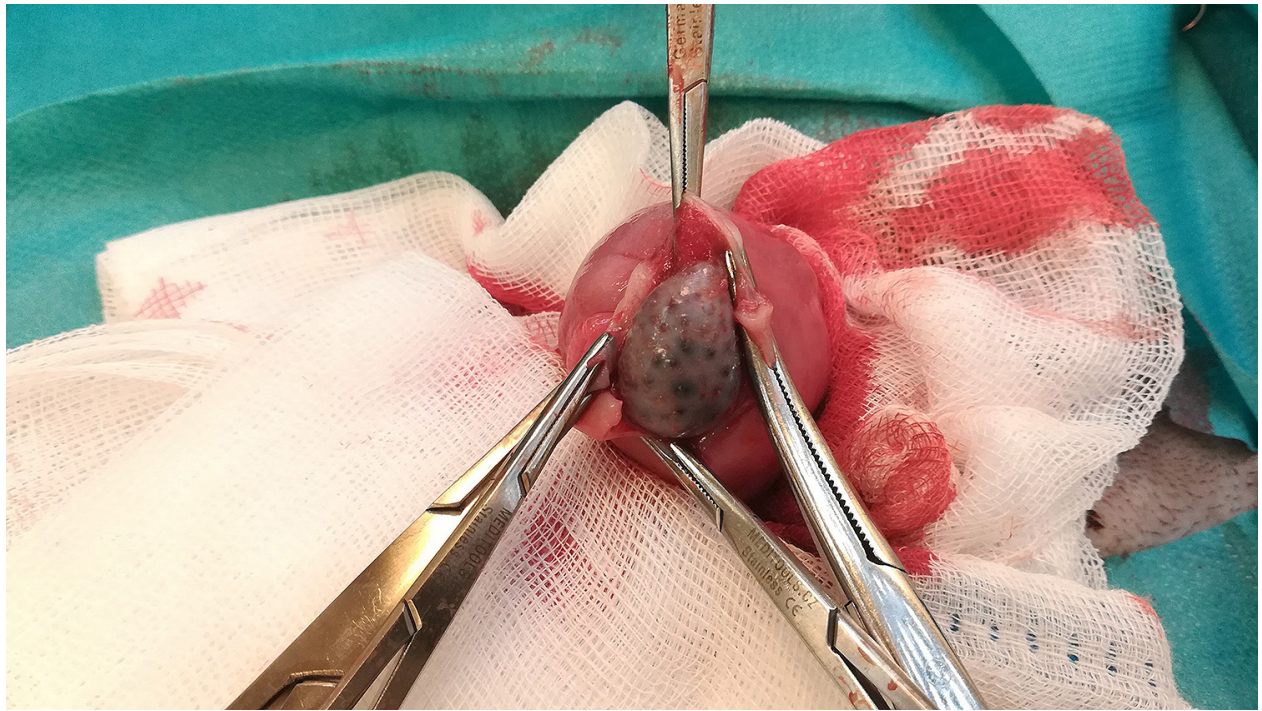

Fig. 6. Exteriorization of the right pregnant uterine horn together with the herniated left horn 
Plate XI

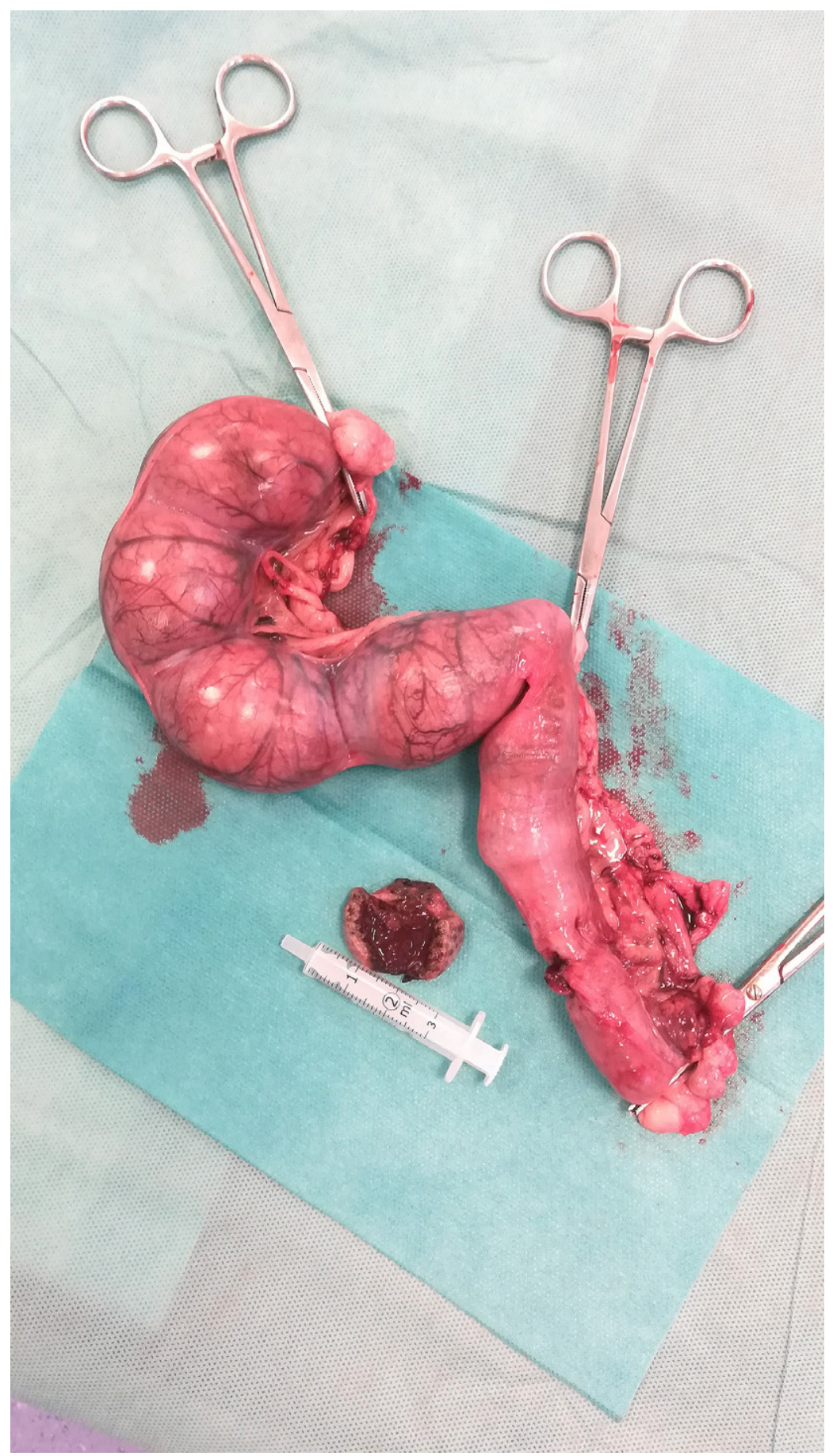

Fig. 7. Both uterine horns after ovariohysterectomy 
Plate XII

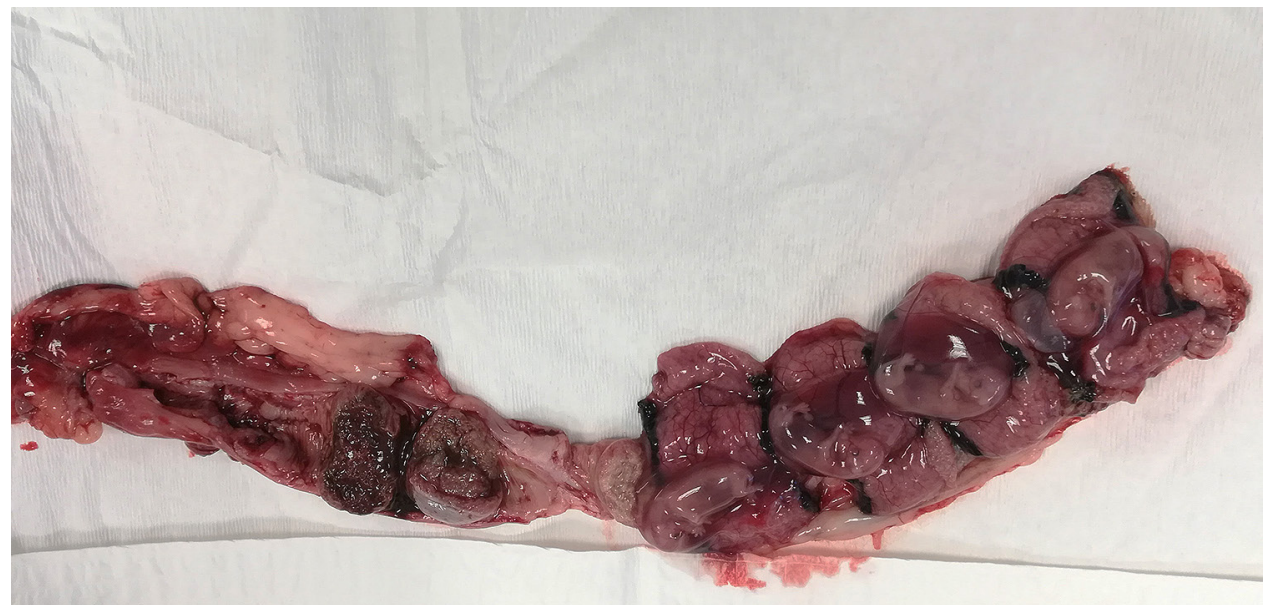

Fig. 8. Right uterine horn with 4 developed conceptuses and left uterine horn with one macerated conceptus

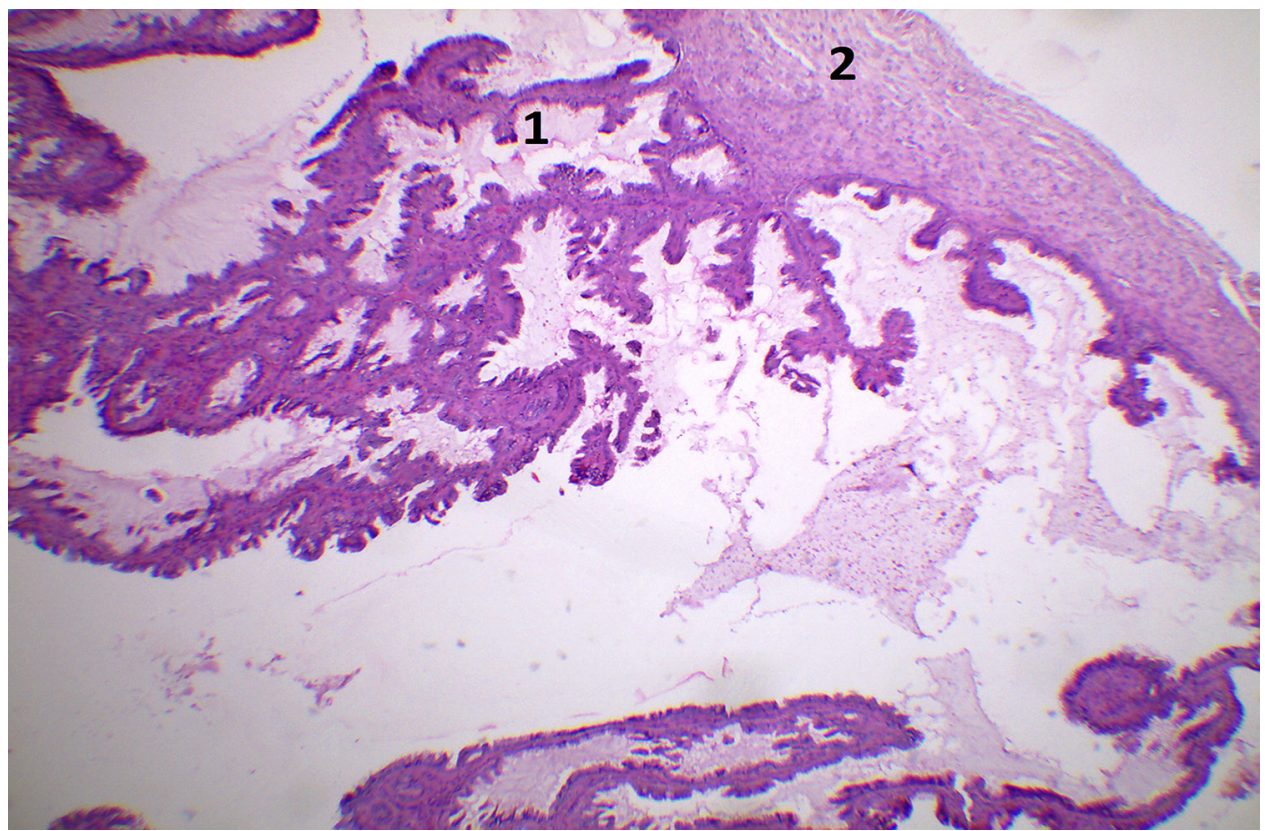

Fig. 9A. The villous structure (1) of trophoblast surrounded with mesoderm $(2)(\mathrm{HE}, \times 4)$. 


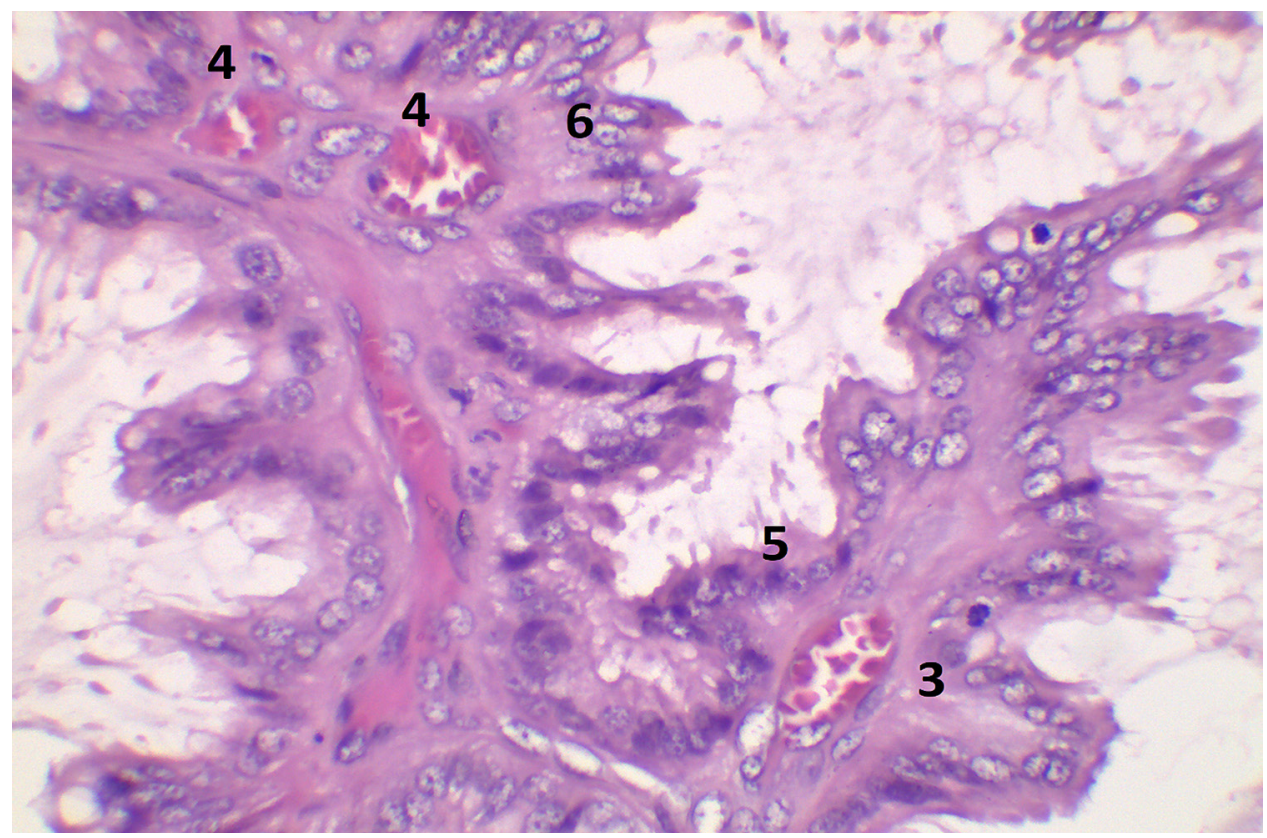

Fig. 9B. The villous stroma (3) with foetal vessels (4), syncytiotrophoblast (5) and cytotrophoblast (6) (HE, $\times 40)$ 